\title{
Complex interactions between pre-spawning water level increase, trophic state and spawning stock biomass determine year-class strength in a shallow-water-spawning fish
}

\author{
By S. Stoll ${ }^{1,2}$ \\ ${ }^{1}$ Limnological Institute, University of Konstanz, Konstanz, Germany; ${ }^{2}$ Department of River Ecology and Conservation, \\ Biodiversity and Climate Research Centre \& Senckenberg Research Institute and Natural History Museum Frankfurt, \\ Gelnhausen, Germany
}

\begin{abstract}
Summary
Pre spawning water level increase (PWLI) is a recently dis covered parameter of water level dynamics affecting juvenile year class strength (YCS) in shallow water spawning fish. By analysing a time series of commercial common bream $(\mathrm{Abr}$ amis brama) yields in Lake Constance from 1950 through 2007, this study showed that the differences in juvenile YCS are conserved until the adult life stage. Adult YCS was best explained by complex interactions of PWLI with both stock intrinsic and extrinsic environmental variables. The correla tion between PWLI and YCS of adult bream became more pronounced as the trophic state of the lake increased. It is argued that this mediator effect of the trophic state results from increased growth of the algal biofilms during high tro phic state periods. These biofilms are known to impair safe attachment of the eggs to the substratum and affect mortality rates of the eggs. Furthermore, reproductive stock size exhib ited a positive effect on the resulting YCS. However, a mar ginally significant interaction between reproductive stock size and PWLI indicates that the two positive effects of PWLI and reproductive stock size on YCS were not fully additive, probably because the very large year classes resulting from the combined positive effects suffered from strong intra spe cific competition. This study demonstrates that anthropo genic water level regulation, e.g. for flood protection or for the generation of hydroelectric power, and climate change altering PWLI have the potential to affect YCS throughout the whole life cycle of bream, particularly in eutrophic water bodies. Similar effects of PWLI are anticipated in other shal low water spawning species.
\end{abstract}

\section{Introduction}

The early life stages of many fish species have been shown to be sensitive to water level dynamics (WLD) (Gafny et al., 1992; Clark et al., 1998; Argillier et al., 2004; Probst et al., 2009). Decreasing water levels during egg incubation can cause mass mortality of the eggs (Kahl et al., 2008). For lar val and juvenile fish, the water level in summer has been regarded as the most important parameter of WLD. Its effects are mostly indirect. With an increasing water level, flat bank areas become inundated, providing structure rich additional habitats where larval and juvenile fish profit from high food availability (Lewin et al., 2004) and shelter against predation (Crowder and Cooper, 1982; Stoll et al., 2008). Furthermore, in these stagnant shallow areas, water temperatures are often increased, leading to increased growth rates (Allen, 1982).

Using common bream (Abramis brama) as an example of shallow water spawning fish, Probst et al. (2009) and Stoll et al. (2010) showed that with a pre spawning water level increase (PWLI), another parameter of WLD than the water level in summer can be even more important for the forma tion of YCS in shallow water spawning fish. Studying young of the year fish, Probst et al. (2009) demonstrated that the mechanism behind the correlation between PWLI and YCS is a better egg attachment and consequently higher egg survival rates on newly flooded spawning substrata relative to egg survival on long term inundated substrata. The reason for this substratum effect is that algal biofilms develop rap idly on inundated surfaces and impede the safe attachment of eggs. If eggs fail to attach, they fall into the interstitial spaces of the substratum, where high mortality rates result from fungal infections and lack of oxygen. On freshly inun dated spawning substrata, in contrast, these biofilms are not yet present. A negative effect on egg survival produced by algal biofilms covering spawning substrata was also shown by Gafny et al. (1992) in Kinneret bleak (Acanthobrama ter raesanctae). Furthermore, many fish species avoid spawning substrata that are covered with biofilms (Gafny et al., 1992; Fisher et al., 1996) or clean them before spawning (Thorp, 1988; Bruton and Gophen, 1992). This fact, together with the observation that spawning in shallow water in periods of increasing water levels is a common spawning strategy in fish, suggests that this mechanism is potentially important in many other species as well.

Although the cause effect chain linking PWLI, the avail ability of biofilm free spawning substrata, egg survival and YCS in the first year of life has been demonstrated, it remains unclear whether other variables interact with pre spawning water level increase in the formation of YCS and whether these initial differences in YCS persist throughout the lives of the fish, especially in long lived species. Some variables that commonly affect YCS of fish can be intrinsic to the stock, such as reproductive stock biomass (Galindo Cortes et al., 2010). Others can be extrinsic, such as food availability (Olsen et al., 2011), which in turn commonly depends on the trophic state of a water body. Sound knowl edge of the interplay of different variables in the formation of YCS is the prerequisite for sustainable fish stock manage ment. Furthermore, as WLD are expected to be altered due to climate change, a sound mechanistic understanding of 
their effects as well as interactive effects with other variables is most important for assessing the possible consequences of climate change in fish stocks. Although the effects of increased temperature on fish are currently addressed by many studies, the effects of changing WLD have received less attention (Gabel et al., 2011; Stoll and Fischer, 2011).

Accordingly, the YCS of common bream was analysed in this study in relation to PWLI in interaction with stock intrinsic and stock extrinsic variables. Using the fishery sta tistics for common bream from Lake Constance since 1950, the following hypothesis were tested: (i) initial differences in YCS of young of the year bream persist throughout their lives until the adult stages; (ii) other environmental variables, such as trophic status and spawning stock biomass, interact with PWLI in the formation of YCS in adult fish.

\section{Materials and methods}

\section{Study area}

The study was conducted in Upper Lake Constance, a warm monomictic prealpine lake in Central Europe with a surface area of $476 \mathrm{~km}^{2}$ and a mean depth of $100 \mathrm{~m}$ (Mührle et al., 2004). Besides Lake Walensee, Lake Constance is the only non regulated lake in the alpine region (Ostendorp et al., 2004). Therefore, the water level of the lake fluctuates widely, on average approximately $150 \mathrm{~cm}$ throughout the year (Fig. 1), but large inter annual variability with minimal annual amplitudes of less than $100 \mathrm{~cm}$ and maximal annual amplitudes of more than $250 \mathrm{~cm}$ occurred during the period 1950 2007. Highest water levels occur during June or July, with the lowest water levels in February or March. Large parts of the increase in water level in spring result from snowmelt in the Alps, as alpine areas comprise $62 \%$ of the catchment of Lake Constance (Mührle et al., 2004), but con tinuous heavy rains can also influence the dynamics of the water level of the lake.

The lake underwent pronounced eutrophication during the second half of the 20th century (Mührle et al., 2004). Subse quently, the phosphorus inputs were drastically reduced through a ban on phosphorus containing detergents, sewage collection and stripping of phosphorus during sewage treat ment. The lake had returned to oligotrophy by the beginning of the 21 st century.

\section{Common bream}

Bream are common in temperate parts of Europe. They occur predominantly in mesotrophic to hypertrophic lakes

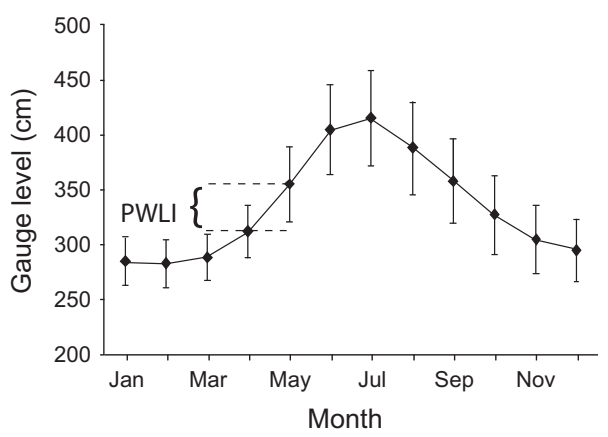

Fig. 1. Gauge level at Konstanz harbour, Lake Constance. Dia monds means of monthly gauge levels ( \pm SD), 1950 2007. Pre spawning water level increase (PWLI) calculated as the difference in monthly mean water levels, April and May and in the potamal sections of rivers, but they are also found in oligotrophic lakes (Löffler, 1984). Bream spawn in very shallow, near shore waters of less than $0.5 \mathrm{~m}$ depth (Poncin et al., 1996; Hladik and Kubecka, 2004) when water temper atures reach approximately $1418^{\circ} \mathrm{C}$ (Herzig and Winkler, 1986; Hladik and Kubecka, 2004). In Lake Constance, spawning aggregations of mature bream can be observed in most years during the period between the end of April and end of May. Thus, spawning coincides with the rapid increase in water level. After a first summer in the littoral zone, juvenile bream move to the pelagic and profundal zone where they stay until they become mature (Fischer and Eck mann, 1997). The age of maturity is approx. six to seven years in females and five years in males. Adult bream return to the littoral zone during spawning in spring and partly also to spend the summer there (Löffler, 1984; unpubl. data).

\section{Commercial bream fishing in Lake Constance}

Data on the total annual commercial bream yield for Upper Lake Constance have been gathered at the Fis chereiforschungsstelle Langenargen since 1950. For this study, data of the years 19502007 were analysed. Most of the bream, approx. 95\% of the commercial trap and fyke net catches and $70 \%$ of the gill net catches, are caught during the spawning season in May (Löffler, 1984). In the year 1950, 218 fishing licences were issued at Lake Constance (Wagner et al., 1993). After the introduction of the more effi cient monofilament nylon gill nets in place of cotton nets around 1960, the number of licences was successively cut by approx. $30 \%$, the number of nets per licence was reduced from ten to three, and fishing effort was reduced from five to four days per week. These measures, together with a receding demand for bream on the fish market, resulted in a continu ously decreasing trend in fishing pressure on bream, however, the fishing pressure is still substantial. This general trend was disrupted during the eutrophication peak around 1980, when the very strong stocks of cyprinid fish were regarded as unwanted food competitors for the more valuable whitefish and perch. A bonus called 'Weißfischprämie' was paid for cyprinid catches from 1974 to 1982. During these years, the fishing effort on bream and other cyprinid fish was substan tially increased (Wagner et al., 1993), and this period was therefore excluded from the analysis.

Direct age determinations for bream caught by commercial fishermen are necessary to relate annual yields to the envi ronmental data from the years when the fish hatch. Unfortu nately, this information is not available because the fishermen only report total monthly yields (S. Blank, Fis chereiforschungsstelle Langenargen, personal communica tion). However, Löffler (1984) reported that most of the bream caught with commercial fishing gear had a total length of $4050 \mathrm{~cm}$, a finding that was confirmed by local fishermen (A. Knoblauch, A. Revermann, pers. comm.). Löffler's growth curve for bream in Upper Lake Constance indicates that these lengths correspond to an age of approx. five to ten years. This age range was used as a starting point to deter mine dominant age classes in the catch in this study.

\section{Environmental data}

A gauge in the harbour of Konstanz, Lake Constance, has recorded the daily lake water level since 1999. Mean water levels on a monthly basis were also available for earlier 
years. The PWLI was calculated as the difference between the mean water levels in April and May. Because most of the bream catch is harvested during spawning season from the spawning stock, bream yields from the anticipated year(s) of birth could be used as a surrogate for the spawning stock biomass. Fishing pressure was decreasing over time, and year of catch was therefore used as a further co variable in the analyses. As a measure of the trophic state of Lake Con stance, volume weighted averages of total phosphorus con centration (TPC) during spring turnover were obtained from Mührle et al. (2004) and supplemented by unpublished data for the most recent years.

\section{Statistics}

To determine dominant year classes in the catch, the propor tion of explained variability was compared in general linear models (GLM) including interactions to the second order. Individual models were run, assuming different years of hatch for the bream in the catch, starting from age class 5 through age class 10 . These GLMs with annual bream yields as the response variable initially comprised PWLI, TPC, spawning stock size and year as independent variables (Yield $\sim \mathrm{PWLI}_{-\mathrm{i} \text { years }} *$ Stock size $_{-\mathrm{i} \text { years }} * \mathrm{TPC}_{0}$ to $-\mathrm{i}$ years $*$ Year; with $5 \leq \mathrm{i} \leq 10$ ).

As PWLI and spawning stock biomass are variables that are assumed to affect the eggs and the early juvenile life stages, individual values of the anticipated hatching year of the bream were used. The TPC, in contrast, may affect the biofilm on which the eggs are attached but also the food availability for bream during their whole life. Therefore, TPC values used in the analyses were averages over the total anticipated lifetime of the bream (5 10 years).

These initial models were backwards selected until a mini mum Akaike Information Criterion was reached.

Because several subsequent age classes may be co domi nant in the catch of a given year, the analyses were repeated with moving averages over two year and three year time spans of the independent variables. Longer time frames were not meaningful because the averaging procedure levelled out the inter annual variability in the data, especially in PWLI.

The modelling was accomplished with $R$ software (R Development Core Team, 2011).

The interaction analyses were based on the best model for two year averaged data. In one scenario, the total annual yields were recalculated, assuming a constantly low, medium or high trophic status (TPC 10, 30, $80 \mu \mathrm{g} \mathrm{L} \mathrm{L}^{-1}$, respec tively), in a second scenario, the total annual yields were recalculated for low, medium and high spawning stock sizes (spawning stock size 10,60, $120 \mathrm{t}$, respectively). For all other variables, the original values were retained. Outlier years with PWLI $<0.1 \mathrm{~m}$ and PWLI $>0.8 \mathrm{~m}$ were excluded from the interaction analysis (Nalimov test; $\mathrm{P}<0.05$ ).

\section{Results}

The annual bream yields varied between $6.9 \mathrm{t} \mathrm{a}^{-1}$ and $147.0 \mathrm{t}$ $\mathrm{a}^{-1}$ in the years investigated. The years when the fishing bonus for cyprinids ('Weißfischprämie') was paid were not considered in the analysis. The bream yields during these years reached a peak value of $328.4 \mathrm{t} \mathrm{a}^{-1}$ (Fig. 2a). PWLI fluctuated without a recognisable pattern and ranged between 10 and $75 \mathrm{~cm}$ in most years. In 1999, an exceptional flood produced a PWLI of $128 \mathrm{~cm}$. In 1957 and 1981, snowmelt
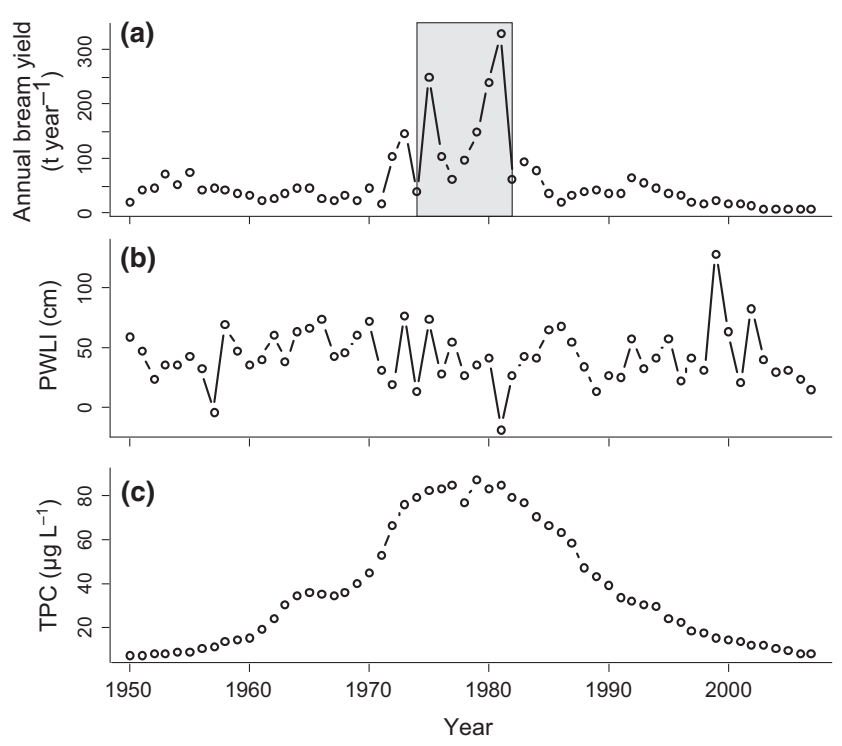

Fig. 2. Data overview for analyses. (a) Annual bream yields, (b) pre spawning water level increase (PWLI), and (c) total phosphorus concentration (TPC), Lake Constance, 1950 2007. Shaded period in a bonus paid 'Weißfischpramie' for cyprinid catches

was delayed until June and resulted in negative PWLI values of 4 and $18 \mathrm{~cm}$, respectively (Fig. 2b). TPC showed a bell shaped curve with approx. $7 \mu \mathrm{g} \mathrm{L}^{-1}$ at the beginning of the 1950s, an eutrophic phase around 1980 with peak values $>80 \mu \mathrm{g} \mathrm{L}^{-1}$, and a current TPC of $8 \mu \mathrm{g} \mathrm{L}^{-1}$.

For the time span of five to ten years, with all three aver aging procedures, a peak in the power of the tested variables to explain the bream yields was found for the year class of seven year old bream $\left(\mathrm{R}^{2} \quad 0.61\right.$; Fig. 3$)$. This peak indicates that this year class was especially prominent in bream yields. Averaging data over two years also provided the highest power overall in explaining the variability of bream yields in neighbouring year classes. However, averaging over three consecutive year classes did not further improve the models.

The individual variables selected in the single year, two year averaged and three year averaged models for seven year old bream were examined in the next step of the analysis. For all three models, the backward elimination retained the same set of variables and also their explanatory power was very similar (Table 1). In all models, the effect of

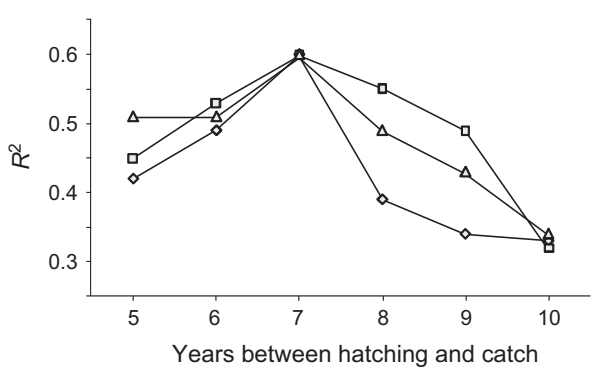

Fig. 3. Proportion of variability in bream yields explained by best model, determined by backward elimination until minimum Akaike Information Criterion was reached. Variable elimination process started from a second order interaction model including the variables year, pre spawning water level increase (PWLI), total phosphorus concentration (TPC) and stock size for different assumed age classes in the catch. The analysis was repeated for data on PWLI, TPC and stock size on a single year basis $(\diamond)$, for averaged data over two year periods $(\square)$ and for averaged data over three year periods $(\Delta)$ 
Table 1

Analysis of variables explaining inter annual variability in bream (Abramis brama) yields. Using general linear models, variables were back wards selected until the minimum Akaike Information Criterion was reached, starting from a full factorial model. Analyses were repeated for variables of each single year as well as for variables averaged over two year and three year time spans. Significant values are highlighted in bold

\begin{tabular}{|c|c|c|c|c|c|c|c|c|c|}
\hline & \multicolumn{3}{|l|}{ Single years } & \multicolumn{3}{|l|}{ Two year average } & \multicolumn{3}{|l|}{ Three year average } \\
\hline & Estimate $\pm \mathrm{SE}$ & $\mathrm{t}$ & $\mathrm{P}$ & Estimate $\pm \mathrm{SE}$ & $\mathrm{t}$ & $\mathrm{P}$ & Estimate $\pm \mathrm{SE}$ & $\mathrm{t}$ & $\mathrm{P}$ \\
\hline Year & $-6.0 \pm 2.2 \mathrm{E}+05$ & -3.0 & 0.007 & $-6.1 \pm 2.1 \mathrm{E}+05$ & -3.0 & 0.006 & $-6.2 \pm 2.0 \mathrm{E}+05$ & -3.0 & 0.005 \\
\hline TPC & $-8.8 \pm 6.5 \mathrm{E}+05$ & -1.4 & 0.19 & $-1.5 \pm 0.9 \mathrm{E}+06$ & -1.8 & 0.090 & $-2.0 \pm 1.1 \mathrm{E}+06$ & -1.9 & 0.073 \\
\hline PWLI & $0.2 \pm 4.5 \mathrm{E}+05$ & 0.1 & 0.97 & $-2.7 \pm 3.7 E+05$ & -0.8 & 0.44 & $-1.7 \pm 6.4 \mathrm{E}+05$ & -0.3 & 0.79 \\
\hline Stock & $7.1 \pm 6.7 \mathrm{E}+03$ & 1.1 & 0.30 & $6.4 \pm 3.1 \mathrm{E}+02$ & 2.2 & 0.037 & $1.1 \pm 1.0 \mathrm{E}+03$ & 1.1 & 0.30 \\
\hline TPC x PWLI & $4.0 \pm 1.3 \mathrm{E}+04$ & 3.1 & 0.004 & $5.3 \pm 2.9 \mathrm{E}+04$ & 3.0 & 0.005 & $6.6 \pm 2.2 \mathrm{E}+04$ & 3.0 & 0.006 \\
\hline PWLI x Stock & $-2.0 \pm 1.4 \mathrm{E}+01$ & 1.4 & 0.17 & $-1.5 \pm 0.8 \mathrm{E}+01$ & -1.8 & 0.079 & $-3.4 \pm 2.4 \mathrm{E}+01$ & -1.4 & 0.18 \\
\hline
\end{tabular}

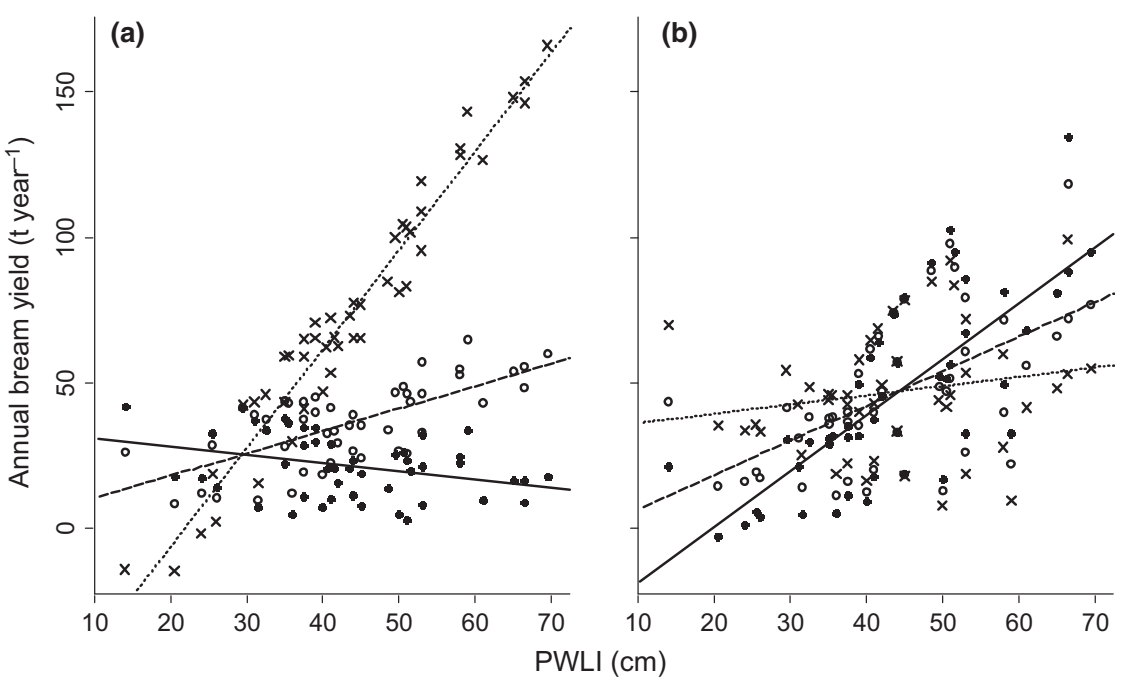

Fig. 4. Interaction analysis on the combined effects of (a) pre spawning water level increase (PWLI) and total phosphorus concentration (TPC) on annual bream yields and (b) the combined effects of PWLI and spawning stock size on annual bream yields. In a, correlations shown for oligotrophic condition (TPC $10 \mu \mathrm{g} \mathrm{L}^{-1}$; •; solid line; $\mathrm{R}^{2} \quad 0.07 ; \mathrm{P} \quad 0.13$ ), mesotrophic condition (TPC $30 \mu \mathrm{g} \mathrm{L}^{-1}$; $\circ$; long dashes; $\left.\mathrm{R}^{2} \quad 0.43 ; \mathrm{P}<0.001\right)$ and eutrophic condition (TPC $80 \mu \mathrm{g} \mathrm{L}^{-1} ; \times$; short dashes; $\mathrm{R}^{2} \quad 0.93 ; \mathrm{P}<0.001$ ). In $\mathrm{b}$, correlations are shown for small reproductive stock size $\left(10 \mathrm{t}\right.$; $\bullet$; solid line; $\left.\mathrm{R}^{2} \quad 0.65 ; \mathrm{P}<0.001\right)$, medium reproductive stock size $\left(60 \mathrm{t}\right.$; $\circ$; long dashes; $\mathrm{R}^{2} \quad 0.49$; $\mathrm{P}<0.001)$ and large reproductive stock size $\left(120 \mathrm{t} ; \times\right.$; short dashes; $\left.\mathrm{R}^{2} \quad 0.25 ; \mathrm{P} \quad 0.003\right)$

PWLI on bream yields was highly significant; however not as an individual variable but in interaction with TPC (Table 1). An interaction analysis was conducted using PWLI as the focal predictor and TPC as the moderator variable. Only when the trophic status of the lake was high, annual bream yields depended on PWLI of the year when these fish hatched (Fig. 4a), whereas the correlation between annual yields and PWLI of the year of hatching faded as TPC decreased. Thus, low PWLI always resulted in small year classes independently of the trophic state of the lake whereas strong year classes leading to high annual yields were only formed in years in which high PWLI and high TPC coin cided.

Furthermore, as expected, the variable 'year' was nega tively correlated with bream yields because fishing pressure was decreasing.

A positive effect of bream recruitment stock biomass on the catches seven years later was found when moving aver ages over two year periods were used to smooth the vari ables (Table 1). Furthermore, a close to significant negative interaction between recruitment stock biomass and PWLI indicated that with increasing stock biomass, the effect of
PWLI on bream yield became less pronounced (Table 1, Fig. 4b).

\section{Discussion}

Long time series and detailed life tables of freshwater fish species are rare. This lack of appropriate data makes it diffi cult to investigate cause effect relationships between environ mental variables and YCS. This study uses more readily available data on the annual yields of a closed population of bream in one lake. Such data may not always be ideal for the quantitative analysis of such relationships. For example, the individual year classes were not clearly delimited in the data. Nevertheless, this analysis demonstrates that fishing yields can be used to unravel the effects of different environ mental variables on YCS on a qualitative basis.

Seven year old bream were the dominant year classes in the catch, and thus, to a predominant extent, individuals that only recently matured are being caught. Younger fish are not yet mature and, thus, do not frequent the spawning sites in the littoral zone where bream are mainly caught. Older fish also seem to contribute less to the fishing yields, either 
because of fishing and natural mortality or simply because they become more experienced in avoiding the fishing gear.

The effect of PWLI on YCS, described by Probst et al. (2009) for young of the year bream, was still detectable in these commercial catches. Thus, initial YCS are at least partly conserved until the reproductive life stages are reached. However, the data revealed complex interactions of PWLI with spawning stock biomass and the trophic status of the lake. Thus, depending on the ecological context, changes in WLD may produce different effects in bream stocks. The results of the analyses were highly concordant among the three different averaging procedures that were applied. This finding underscored the overall robustness of the results. The one exception to this general pattern of agreement was that the effects of stock size could only be detected in two year averaged data. Thus, even though this is a very plausible result, it has to be interpreted more carefully.

A high trophic status of the lake amplified the effect of PWLI on bream YCS. This result is evident because at high trophic status, the spawning substratum quality depends even more on PWLI than at low trophic status. The growth of biofilms on the surfaces of submersed substrata is enhanced by increases in nutrient availability (Vadeboncoeur et al., 2008). Enhanced biofilm growth narrows the time window for the availability of biofilm free spawning substrata after an increase in water level and thicker algal biofilms are expected to further reduce egg attachment. The general qual ity of bottom substrata as spawning habitat can also be reduced if the trophic status of a lake is high. This decrease in quality is a result of the deposition of fine organic parti cles (Vadeboncoeur et al., 2003; Rowe and Taumoepeau, 2004). These organic sediments further impede egg attach ment and cause oxygen deficiency (Johnson, 1961; Hassler, 1970).

The trophic condition of the lake affects egg survival, but it also affects fish at later life stages by altering the avail ability of food (Persson et al., 1991; Dauba and Bíró, 1992; Olin et al., 2002). At low TPC, different levels of PWLI also lead to smaller or larger YCS of young of the year bream (Probst et al., 2009), but these initial differences in YCS do not persist until the adult stages. Instead, this study found that, independent of PWLI in the year of hatching, bream YCS at adult stages was always low under oligotrophic con ditions. This finding indicates a limitation of population size through food restriction. In trophilic bream, positive corre lations between the productivity of lakes and bream stock sizes are well known (Persson et al., 1991; Olin et al., 2002). In Lake Constance, bream feed mainly on chironomids, molluscs (especially Dreissena polymorpha) and zooplankton (Löffler, 1984; Schulz and Berg, 1987; Stoll et al., 2008), whose abundances are also positively related to the trophic state of the lake. However, even though the stock biomass increased with TPC, Löffler (1984) showed that individual bream growth rate did not change with TPC.

Furthermore, reproductive stock size exhibited a positive effect on the resulting YCS. However, a marginally signifi cant interaction with a negative slope between reproductive stock size and PWLI indicates that the two positive effects of PWLI and reproductive stock size on YCS were not fully additive, probably because the very large year classes result ing from the combined positive effects suffered from strong intra specific competition.

Using bream in Lake Constance as an example, this study demonstrated that in the variability in PWLI can be an important driver for different YCS. This finding not only applies to young of the year fish but remains valid through out the entire life cycle of the fish. In its role as a parameter of WLD, PWLI is also expected to be an important factor in the formation of YCS in other shallow water spawning fish species. However, this study demonstrates that the effects of PWLI on YCS are complex and that the effects of different environmental variables are interacting. Accordingly, the effects of PWLI depend on the ecological context, and gener alisations should therefore be made with care. For example, shallow water spawning fish may use different spawning sub strata in different habitats. In small lakes, some shallow water spawning fish, including bream, may spawn on freshly grown plant shoots and leaves. In such situations, biofilm free spawning substrata to which eggs adhere may well be available also during periods without pronounced PWLI.

Although both the timing and the amplitudes of WLD in aquatic systems are predicted to change in response to global warming (Christensen et al., 2007), their potential effects on aquatic biota have so far received little attention. Further more, WLD of freshwater systems are also altered directly because an increasing proportion of freshwater systems become regulated to provide drinking and irrigation water, to supply hydroelectric energy or to prevent flooding (Leira and Cantonati, 2008). Through these alterations to natural systems, water levels become buffered or artificially pulsed. Therefore, a better mechanistic understanding of the effects of WLD and of their interactive effects with other environ mental variables on fish and other freshwater biota is a timely goal. Such a mechanistic understanding of the pro cesses affecting the formation of year class strength of shal low water spawning fish is necessary both to develop models of the potential effects of climate change and for the stock management of these fish species.

\section{Acknowledgements}

This study was supported by the Collaborative Research Centre 454 "Littoral Zone of Lake Constance", the funding program "LOEWE Landes Offensive zur Entwicklung Wissenschaftlich oekonomischer Exzellenz" of Hesse's Minis try of Higher Education, Research, and the Arts, and a personal grant to the author by the German National Academic Foundation. The author thanks S. Blank (Fis chereiforschungsstelle Langenargen) who provided the bream yield data. W. Nagl, K. Rinke and D. Straile gave statistical support. P. Fischer, R. Eckmann, H. Kappes and W. N. Probst and two reviewers gave valuable comments on the manuscript.

\section{References}

Allen, L. G., 1982: Seasonal abundance, composition, and productiv ity of the littoral fish assemblage in Upper Newport Bay, Cali fornia. Fish. Bull. 80, 769790.

Argillier, C.; Poulet, N.; Irz, P., 2004: Effect of meteorological condi tions and water level fluctuations on the year class strength of pikeperch (Sander lucioperca L.) and perch (Perca fluviatilis L.) in a French reservoir. Ecohydrol. Hydrobiol. 4, 441448.

Bruton, M. N.; Gophen, M., 1992: The effect of environmental fac tors on the nesting and courtship behaviour of Tilapia zillii in Lake Kinneret, Israel. Hydrobiologia 239, 171178.

Christensen, J. H.; Hewitson, B.; Busuioc, A.; Chen, A.; Gao, X.; Held, I.; Jones, R.; Kolli, R. K.; Kwon, W. T.; Laprise, R.; Magana Rueda, V.; Mearns, L.; Menéndez, C. G.; Raisanen, J.; Rinke, A.; Sarr, A.; Whetton, P., 2007: Regional Climate 
Projections. In: Climate change 2007: the Physical science basis. Contribution of working group I to the fourth assessment report of the intergovernmental panel on climate change. S. Solomon, D. Qin, M. Manning, Z. Chen, M. Marquis, K. B. Averyt, M Tignor, H. L. Miller (Eds). Cambridge University Press, Cambridge, United Kingdom and New York, NY, USA. pp. 849940.

Clark, M. E.; Rose, K. A.; Chandler, J. A.; Richter, T. J.; Orth, D J.; Van Winkle, W., 1998: Simulating smallmouth bass repro ductive success in reservoirs subject to water level fluctuations. Environ. Biol. Fishes 51, 161174.

Crowder, L. B.; Cooper, W. E., 1982: Habitat structural complexity and the interaction between bluegills and their prey. Ecology 63 18021813.

Dauba, F.; Bíró, P., 1992: Growth of bream, Abramis brama L., in two outside basins of different trophic state of Lake Balaton. Int. Revue ges. Hydrobiol. 77, 225235.

Fischer, P.; Eckmann, R., 1997: Spatial distribution of littoral fish species in a large European lake, Lake Constance, Germany. Arch. Hydrobiol. 140, 91116.

Fisher, S. J.; Pope, K. L.; Templeton, L. J.; Willis, D. W., 1996: Yel low perch spawning habitats in Pickerel Lake, South Dakota. Prairie Nat. 28, 6575.

Gabel, F.; Stoll, S.; Fischer, P.; Pusch, M. T.; Garcia, X. F., 2011 Waves affect predator prey interactions between fish and ben thic invertebrates. Oecologia 165, 101109.

Gafny, S.; Gasith, A.; Goren, M., 1992: Effect of water level fluctua tion on shore spawning of Mirogrex terrasanctae (Steinitz), (Cyprinidae) in Lake Kinneret, Israel. J. Fish Biol. 41, 863871.

Galindo Cortes, G.; De Anda Montanez, J. A.; Arreguin Sanchez, F.; Salas, S.; Balart, E. F., 2010: How do environmental factors affect the stock recruitment relationship? The case of the Pacific sardine (Sardinops sagax) of the northeastern Pacific Ocean Fish. Res. 10, 173183.

Hassler, T. J., 1970: Environmental influence on early development and year class strength of northern pike in lakes Oahe and Sharpe, South Dakota. Trans. Am. Fish. Soc. 99, 369375.

Herzig, A.; Winkler, H., 1986: The influence of temperature on the embyonic development of three cyprinid fishes, Abramis brama, Chalcalburnus chalcoides mento and Vimba vimba. J. Fish Biol. 28, 171181 .

Hladik, M.; Kubecka, J., 2004: The effect of water level fluctuation on tributary spawning migration of reservoir fish. Ecohydrol. Hydrobiol. 4, 449457.

Johnson, F. H., 1961: Walleye egg survival during incubation on sev eral types of bottom in Lake Winnibigoshish, Minnesota, and connecting waters. Trans. Am. Fish. Soc. 90, 312322.

Kahl, U.; Hulsmann, S.; Radke, R. J.; Benndorf, J., 2008: The impact of water level fluctuations on the year class strength of roach: Implications for fish stock management. Limnologica 38, 258268.

Leira, M.; Cantonati, M., 2008: Effects of water level fluctuations on lakes: an annotated bibliography. Hydrobiologia 613, 171184.

Lewin, W. C.; Okun, N.; Mehner, T., 2004: Determinants of the dis tribution of juvenile fish in the littoral area of a shallow lake. Freshw. Biol. 49, 410424.

Loffler, H., 1984: Zur Okologie des Brachsen (Abramis brama (L.)) im Bodensee. Schweiz. Z. Hydrol. 46, 147162.

Muhrle, U.; Ortlepp, J.; Rey, P., 2004: Der Bodensee Zustand, Fak ten, Perspektiven. Bregenz, Internationale Gewasserschutzkom mission fur den Bodensee (IGKB)

Olin, M.; Rask, M.; Ruuhijarvi, J.; Kurkilahti, M.; Ala Opas, P.; Ylonen, O., 2002: Fish community structure in mesotrophic and eutrophic lakes of southern Finland: the relative abundances of percids and cyprinids along a trophic gradient. J. Fish Biol. 60, 593612.

Olsen, E. M.; Ottersen, G.; Llope, M.; Chan, K. S.; Beaugrand, G.; Stenseth, N. C., 2011: Spawning stock and recruitment in North Sea cod shaped by food and climate. Proc. Roy. Soc. B 287, 504510 .

Ostendorp, W.; Schmieder, K.; Johnk, K., 2004: Assessment of human pressures and their hydromorphological impacts in lake shores in Europe. Ecohydrol. Hydrobiol. 4, 379395.

Persson, L.; Diehl, S.; Johansson, L.; Andersson, G.; Hamrin, S. F. 1991: Shifts in fish communities along the productivity gradien of temperate lakes patterns and the importance of size struc tured interactions J. Fish Biol. 38, 281293.

Poncin, P.; Philippart, J. C.; Ruwet, J. C., 1996: Territorial and non territorial spawning behaviour in the bream. J. Fish Biol. 49, 622626.

Probst, W. N.; Stoll, S.; Peters, L.; Fischer, P.; Eckmann, R., 2009: Lake water level increase during spring affects the breeding success of bream Abramis brama (L.). Hydrobiologia 632, 211224.

Rowe, D. K. Taumoepeau, A., 2004: Decline of common smelt (Retropinna retropinna) in turbid, eutrophic lakes in the North Island of New Zealand. Hydrobiologia 523, 149158

Schulz, U.; Berg, R., 1987: The migration of ultrasonic tagged bream, Abramis brama in Lake Constance (Bodensee Untersee). J. Fish Biol. 31, 409414.

Stoll, S.; Fischer, P., 2011: Three different patterns of how low inten sity waves can affect the energy budget of littoral fish: a meso cosm study. Oecologia 165, 567576.

Stoll, S.; Fischer, P.; Klahold, P.; Scheifhacken, N.; Hofmann, H.; Rothhaupt, K. O., 2008: Effects of water depth and hydrodynam ics on the growth and distribution of juvenile cyprinids in the lit toral zone of a large pre alpine lake. J. Fish Biol. 72, 10011022.

Stoll, S.; Probst, W. N.; Eckmann, R.; Fischer, P., 2010: A meso cosm experiment investigating the effects of substratum quality and wave exposure on the survival of fish eggs. Aquat. Sci. 72 509517.

Team, R. D. C., 2011: R: A language and environment for statistical computing. R Foundation for Statistical Computing, Vienna, Austria.

Thorp, J. H., 1988: Patches and the responses of lake benthos to sunfish nest building. Oecologia 76, 168174.

Vadeboncoeur, Y.; Jeppesen, E.; Vander Zanden, M. J.; Schierup, H. K.; Christoffersen, K.; Lodge, D. M., 2003: From Greenland to green lakes: cultural eutrophication and the loss of benthic pathways in lakes. Limnol. Oceanogr. 48, 14081418.

Vadeboncoeur, Y.; Peterson, G.; Vander Zanden, M. J.; Kalff, J., 2008: Benthic algal production across lake size gradients: inter actions among morphometry, nutrients, and light. Ecology 89 25422552.

Wagner, B.; Loffler, H.; Kindle, T.; Klein, M.; Staub, E., 1993 Bodenseefischerei Geschichte, Biologie und Okologie, Bewirts chaftung. Jan Thorbecke Verlag, Sigmaringen.

Author's address: Stefan Stoll, Limnological Institute, University of Konstanz, D 78457 Konstanz, Germany and Department of River Ecology and Conservation, Biodiversity and Climate Research Centre \& Senc kenberg Research Institute and Natural History Museum Frankfurt, Clamecystraße 12, D 63571 Gelnhausen, Germany.

E mail: stefan.stoll@senckenberg.de 